\title{
Correction to: Vitamin D deficiency and risk of cardiovascular diseases: a narrative review
}

Babikir Kheiri", Ahmed Abdalla, Mohammed Osman, Sahar Ahmed, Mustafa Hassan and Ghassan Bachuwa

\section{Correction to: Clin Hypertens \\ https://doi.org/10.1186/s40885-018-0094-4}

In the original publication of this article [1], the reference number [42] under the section 'Vitamin D and cardiovascular diseases' (page No.2) should be [37].

Received: 14 December 2018 Accepted: 18 December 2018

Published online: 24 December 2018

\section{Reference}

1. Kheiri, et al. Vitamin D deficiency and risk of cardiovascular diseases: a narrative review. Clin Hypertens. 2018;24:9 https://doi.org/10.1186/s40885018-0094-4. 